\title{
Bivalirudin during Primary PCI in Acute Myocardial Infarction
}

\author{
Gregg W. Stone, M.D., Bernhard Witzenbichler, M.D., \\ Giulio Guagliumi, M.D., Jan Z. Peruga, M.D., Bruce R. Brodie, M.D., \\ Dariusz Dudek, M.D., Ran Kornowski, M.D., Franz Hartmann, M.D., \\ Bernard J. Gersh, M.B., Ch.B., D.Phil., Stuart J. Pocock, Ph.D., \\ George Dangas, M.D., Ph.D., S. Chiu Wong, M.D., Ajay J. Kirtane, M.D., \\ Helen Parise, Sc.D., and Roxana Mehran, M.D., \\ for the HORIZONS-AMI Trial Investigators*
}

ABSTRACT

From Columbia University Medical Center and the Cardiovascular Research Foundation, New York (G.W.S., G.D., A.J.K., H.P., R.M.); Charité Campus Benjamin Franklin, Berlin (B.W.); Ospedali Riuniti di Bergamo, Bergamo, Italy (G.G.); Silesian Center for Heart Disease, Lodz, Poland (J.Z.P.); LeBauer Cardiovascular Research Foundation and Moses Cone Hospital, Greensboro, NC (B.R.B.); Jagiellonian University, Krakow, Poland (D.D.); Rabin Medical Center, Petach Tikva, Israel (R.K.); Universitätsklinikum Schleswig-Holstein, Lübeck, Germany (F.H.); Mayo Clinic, Rochester, MN (B.J.G.); London School of Hygiene and Tropical Medicine, London (S.J.P.); and New York-Presbyterian Hospital/ Weill Cornell Medical Center, New York (S.C.W.). Address reprint requests to Dr. Stone at Columbia University Medical Center, Cardiovascular Research Foundation, 111 E. 59th St., 11th Fl., New York, NY 10022, or at gs2184@columbia.edu.

*The investigators, institutions, and research organizations participating in the Harmonizing Outcomes with Revascularization and Stents in Acute Myocardial Infarction (HORIZONS-AMI) Trial are listed in the Appendix.

N Engl J Med 2008;358:2218-30.

Copyright (๑) 2008 Massachusetts Medical Society.

\section{BACKGROUND}

Treatment with the direct thrombin inhibitor bivalirudin, as compared with heparin plus glycoprotein IIb/IIIa inhibitors, results in similar suppression of ischemia while reducing hemorrhagic complications in patients with stable angina and non-STsegment elevation acute coronary syndromes who are undergoing percutaneous coronary intervention (PCI). The safety and efficacy of bivalirudin in high-risk patients are unknown.

\section{METHODS}

We randomly assigned 3602 patients with ST-segment elevation myocardial infarction who presented within 12 hours after the onset of symptoms and who were undergoing primary PCI to treatment with heparin plus a glycoprotein IIb/IIIa inhibitor or to treatment with bivalirudin alone. The two primary end points of the study were major bleeding and combined adverse clinical events, defined as the combination of major bleeding or major adverse cardiovascular events, including death, reinfarction, target-vessel revascularization for ischemia, and stroke (hereinafter referred to as net adverse clinical events) within 30 days.

RESULTS

Anticoagulation with bivalirudin alone, as compared with heparin plus glycoprotein IIb/IIIa inhibitors, resulted in a reduced 30-day rate of net adverse clinical events (9.2\% vs. $12.1 \%$; relative risk, $0.76 ; 95 \%$ confidence interval [CI] 0.63 to $0.92 ; \mathrm{P}=0.005$ ), owing to a lower rate of major bleeding ( $4.9 \%$ vs. $8.3 \%$; relative risk, $0.60 ; 95 \% \mathrm{CI}$, 0.46 to $0.77 ; \mathrm{P}<0.001$ ). There was an increased risk of acute stent thrombosis within 24 hours in the bivalirudin group, but no significant increase was present by 30 days. Treatment with bivalirudin alone, as compared with heparin plus glycoprotein IIb/IIIa inhibitors, resulted in significantly lower 30-day rates of death from cardiac causes (1.8\% vs. $2.9 \%$; relative risk, $0.62 ; 95 \% \mathrm{CI}, 0.40$ to $0.95 ; \mathrm{P}=0.03$ ) and death from all causes ( $2.1 \%$ vs. $3.1 \%$; relative risk, $0.66 ; 95 \% \mathrm{CI}, 0.44$ to $1.00 ; \mathrm{P}=0.047)$.

\section{CONCLUSIONS}

In patients with ST-segment elevation myocardial infarction who are undergoing primary PCI, anticoagulation with bivalirudin alone, as compared with heparin plus glycoprotein IIb/IIIa inhibitors, results in significantly reduced 30-day rates of major bleeding and net adverse clinical events. (ClinicalTrials.gov number, NCT00433966.) 
P RIMARY PERCUTANEOUS CORONARY INtervention (PCI) in patients with evolving STsegment elevation myocardial infarction decreases infarct size and the rates of recurrent ischemia, reinfarction, and stroke and improves survival, as compared with pharmacologic reperfusion therapy. ${ }^{1,2}$ Nonetheless, the prognosis after primary PCI has remained essentially unchanged over the past decade, with neither stents nor other novel devices or drugs improving survival beyond that achievable with balloon angioplasty alone. ${ }^{3-8}$ Treatment with glycoprotein IIb/IIIa inhibitors may decrease the short- and long-term risk of death, 9,10 and these agents are used in more than $90 \%$ of patients who undergo primary PCI in the United States and in the majority of such patients in Europe. ${ }^{11,12}$ Nonetheless, glycoprotein IIb/IIIa inhibitors increase the risk of hemorrhagic complications and thrombocytopenia,,$^{3,10,13-15}$ which have been strongly associated with early and late mortality. ${ }^{15-19}$

The direct thrombin inhibitor bivalirudin (Angiomax, the Medicines Company), when used instead of heparin plus glycoprotein IIb/IIIa inhibitors, has been shown in large-scale, randomized trials to reduce major and minor bleeding and thrombocytopenia while resulting in similar rates of ischemia after PCI in patients with stable angina, those with unstable angina, and those with non-ST-segment elevation myocardial infarction. ${ }^{20-23}$ Whether bivalirudin is safe and effective for patients with ST-segment elevation myocardial infarction who are undergoing primary PCI has not, to our knowledge, been studied. We therefore performed a large-scale study to evaluate the clinical value of bivalirudin in patients with STsegment elevation myocardial infarction.

METHODS

\section{TRIAL}

The Harmonizing Outcomes with Revascularization and Stents in Acute Myocardial Infarction (HORIZONS-AMI) study was a prospective, openlabel, randomized, multicenter trial that compared bivalirudin alone with heparin plus a glycoprotein IIb/IIIa inhibitor in patients with ST-segment elevation myocardial infarction who were undergoing primary PCI. The trial was designed by the principal investigator (Dr. Stone), executive committee, and pharmacology committee and was sponsored and managed by the Cardiovascular Research Foundation, a nonprofit foundation affiliated with Columbia University (receiving funding from many commercial entities that make products for use in cardiovascular medicine, in addition to various other sources), with grant support from Boston Scientific and the Medicines Company. Other than supplying financial support and the drugs and devices, the funding companies were not involved with study processes, including site selection and management, data collection, and analysis. The principal investigator had unrestricted access to the data after the database was locked, controlled the decision to publish, prepared the manuscript, and vouches for the integrity and completeness of the trial report. No agreements exist regarding confidentiality of the data among the funding companies, the sponsor, and the investigators.

\section{PATIENT POPULATION}

Consecutive patients 18 years of age or older who presented within 12 hours after the onset of symptoms and who had ST-segment elevation of $1 \mathrm{~mm}$ or more in two or more contiguous leads, new left bundle-branch block, or true posterior myocardial infarction were considered for enrollment. The principal exclusion criteria were contraindications to the study medications; prior administration of thrombolytic agents, bivalirudin, glycoprotein IIb/ IIIa inhibitors, low-molecular-weight heparin, or fondaparinux for the present admission (although prior unfractionated heparin was allowed); current use of warfarin; history of bleeding diathesis, coagulopathy, heparin-induced thrombocytopenia, intracerebral mass, aneurysm, arteriovenous malformation, or hemorrhagic stroke; stroke or transient ischemic attack within the previous 6 months or any permanent neurologic deficit; refusal to receive blood transfusions; gastrointestinal or genitourinary bleeding within the previous 2 months; major surgery within the previous 6 weeks; a known platelet count of less than 100,000 cells per cubic millimeter or a hemoglobin level of less than $10 \mathrm{~g}$ per deciliter, a planned elective surgical procedure that would necessitate an interruption in treatment with thienopyridines during the first 6 months after enrollment; coronary stent implantation within the previous 30 days; and noncardiac coexisting conditions that could limit life expectancy to less than 1 year or that might interfere with 
compliance with the protocol. The study was approved by the institutional review board or ethics committee at each participating center, and all patients gave written informed consent.

\section{STUDY PROTOCOL AND RANDOMIZATION}

Patients were randomly assigned, in an open-label fashion and in a 1:1 ratio, to treatment with unfractionated heparin plus a glycoprotein IIb/IIIa inhibitor (the control group) or to treatment with bivalirudin alone (Fig. 1). Heparin was administered as an intravenous bolus of 60 IU per kilogram of body weight, with subsequent boluses targeted to an activated clotting time of 200 to 250 seconds. Bivalirudin was administered as an intravenous bolus of $0.75 \mathrm{mg}$ per kilogram, followed by an infusion of $1.75 \mathrm{mg}$ per kilogram per hour. If heparin was administered in a patient in the bivalirudin group, bivalirudin was started 30 minutes later but in all cases before PCI. Both antithrombin agents were discontinued, as specified by the protocol, at the completion of angiography or PCI but could be continued at low doses if they were clinically indicated. A glycoprotein IIb/IIIa inhibitor was administered before PCI in all the patients in the control group but was to be administered in the bivalirudin group only in patients with no reflow or with giant thrombus after PCI. Either abciximab (a bolus of $0.25 \mathrm{mg}$ per kilogram followed by an infusion of $0.125 \mu \mathrm{g}$ per kilogram per minute; maximum dose, $10 \mu \mathrm{g}$ per minute) or doublebolus eptifibatide (a bolus of $180 \mu \mathrm{g}$ per kilogram followed by an infusion of $2.0 \mu \mathrm{g}$ per kilogram per minute, with a second bolus given 10 minutes after the first; no maximum dose prespecified), adjusted for renal impairment according to the label, was permitted at the discretion of the investigator and was continued for 12 hours (abciximab) or 12 to 18 hours (eptifibatide).

Aspirin (324 mg given orally or $500 \mathrm{mg}$ administered intravenously) was given in the emergency room, after which 300 to $325 \mathrm{mg}$ was given orally every day during the hospitalization, and 75 to $81 \mathrm{mg}$ every day thereafter indefinitely. A loading dose of clopidogrel (either $300 \mathrm{mg}$ or $600 \mathrm{mg}$, at the discretion of the investigator), or ticlopidine (500 mg), in the case of allergy to clopidogrel, was administered before catheterization, followed by 75 mg orally every day for at least 6 months (1 year or longer recommended).

Telephone randomization was performed with the use of a computerized, interactive voice- response system and a dynamic (minimization) allocation scheme that balanced the assignments for the administration of heparin before randomization; the administration of $300 \mathrm{mg}$ or $600 \mathrm{mg}$ of clopidogrel or $500 \mathrm{mg}$ of ticlopidine before catheterization; planned administration of abciximab or eptifibatide for patients assigned to the control group; and the location of the study site (in the United States or outside the United States).

Emergency coronary angiography with left ventriculography was performed after randomization, followed by triage, at the discretion of the physician, to PCI, coronary-artery bypass grafting (CABG), or medical management, as described previously. ${ }^{3}$ After patency was restored in the infarct-related vessel, eligible patients were randomly assigned again, in a 3:1 ratio, to either paclitaxeleluting stents (TAXUS Express, ${ }^{2}$ Boston Scientific) or uncoated, bare-metal stents that were identical in appearance (Express, ${ }^{2}$ Boston Scientific). The protocol specified that enrollment would continue until 3000 patients had been randomly assigned to a treatment group in this second part of the study. Clinical follow-up was performed at 30 days ( \pm 7 days), 6 months ( \pm 14 days), and 1 year ( \pm 14 days) and then yearly for a total of 5 years. Prespecified analyses of the primary end points were planned at 30 days for the first randomization (the pharmacologic component of the study) and at 1 year for the second randomization (the stent component). The results of the second randomization currently remain blinded, and the 30-day results reported here are based on pooled data for the stent groups. There were no significant interactions between stent type and the primary end points at 30 days in the pharmacologic component, according to an unblinded, independent statistical monitoring group.

\section{STATISTICAL ANALYSIS}

Two primary 30-day end points were prespecified: major bleeding (not related to coronary-artery bypass grafting) and combined adverse clinical events, defined as the combination of major bleeding or a composite of major adverse cardiovascular events, including death, reinfarction, targetvessel revascularization for ischemia, and stroke (hereinafter referred to as net adverse clinical events). Major bleeding was defined as intracranial or intraocular hemorrhage; bleeding at the access site, with a hematoma that was $5 \mathrm{~cm}$ or larger or that required intervention; a decrease in 


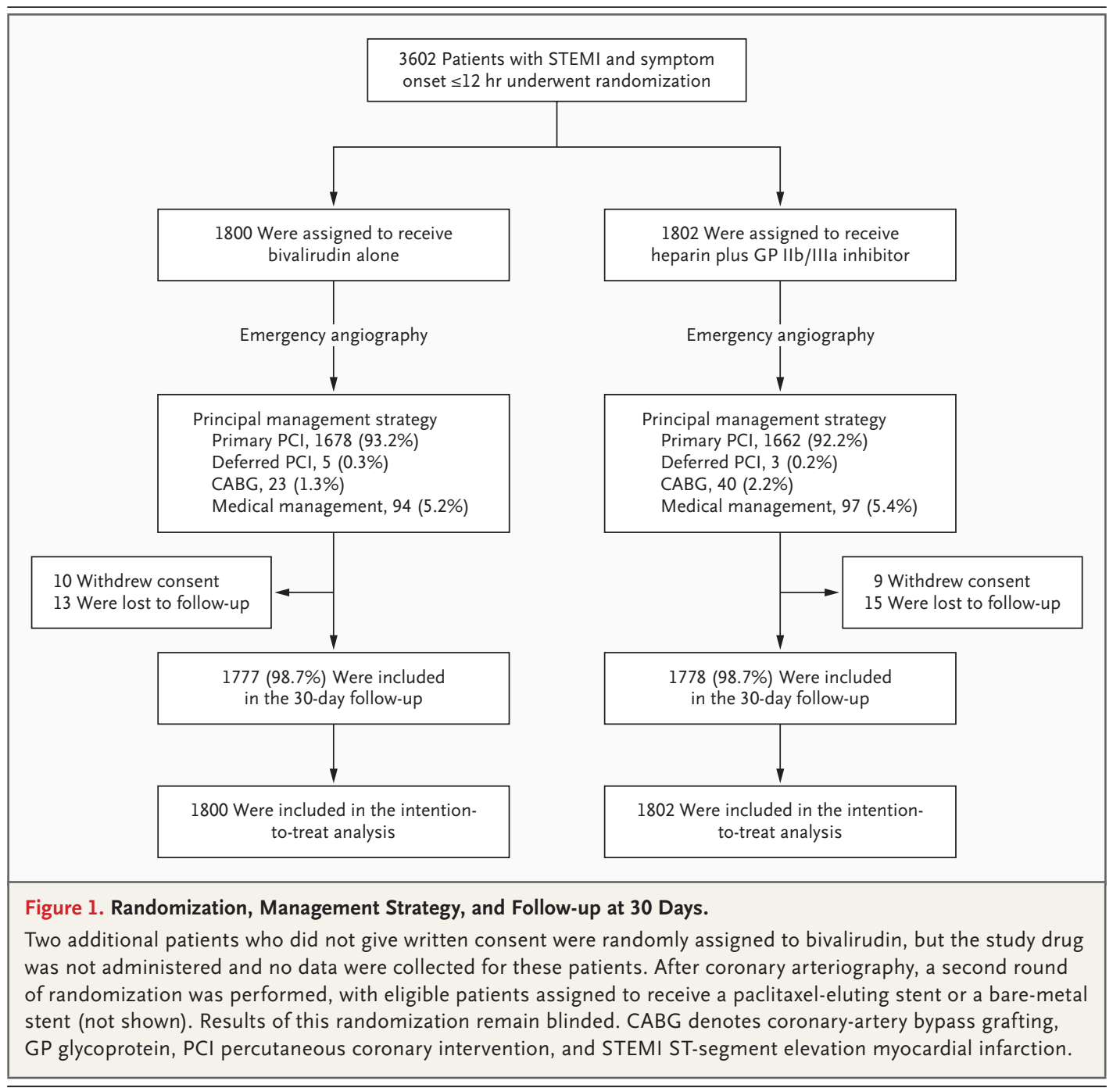

the hemoglobin level of $4 \mathrm{~g}$ per deciliter or more without an overt bleeding source or $3 \mathrm{~g}$ per deciliter or more with an overt bleeding source; reoperation for bleeding; or blood transfusion. Bleeding was also assessed and adjudicated on the basis of the Thrombolysis in Myocardial Infarction (TIMI) and Global Utilization of Streptokinase and Tissue Plasminogen Activator for Occluded Coronary Arteries (GUSTO) scales. Major adverse cardiovascular events have been defined previously. ${ }^{24}$ Death from cardiac causes was defined as death due to acute myocardial infarction, cardiac perforation or pericardial tamponade, arrhythmia or conduction abnormality, stroke, procedural complications, or any death for which a cardiac cause could not be ruled out. Death from noncardiac causes included bleeding-related death. Stent thrombosis was defined as the definite or probable occurrence of a stent-related thrombotic event according to the Academic Research Consortium classification. ${ }^{25}$ An independent clinical events committee that was unaware of the treatment assignments adjudicated all end-point events by reviewing the medical records.

The primary analyses were performed for all patients who underwent randomization, according to the intention-to-treat principle; secondary analyses were performed for the patients who underwent primary PCI. Sequential noninferiority and superiority analysis with hierarchical endpoint testing for both primary end points was prespecified, with type I error controlled by the Benjamini-Hochberg procedure. ${ }^{26}$ Noninferiority tests were based on the upper boundary of the 
two-sided $95 \%$ confidence interval, with the use of binomial proportions. The noninferiority margins for major bleeding and net adverse clinical events were prespecified at $1 \%$ and $3.2 \%$, respectively. A two-sided alpha level of 0.05 was used for superiority testing. Assuming true 30-day event rates for major bleeding and net adverse clinical events of $9 \%$ and $12 \%$, respectively, in the control group and $6 \%$ and $9 \%$, respectively, in the bivalirudin group, with 1700 patients in each group, the trial had $99 \%$ power to show the superiority of bivalirudin for reducing the rate of major bleeding and $80 \%$ power to show its superiority for reducing the rate of net adverse clinical events.

Categorical outcomes were compared by means of the chi-square test or Fisher's exact test. Continuous variables were compared by means of the Wilcoxon rank-sum test. In addition to the primary analysis, which was based on binomial proportions, time-to-event outcomes, determined with Kaplan-Meier methods, were compared by means of the log-rank test.

\section{RESULTS}

\section{PATIENTS AND PROCEDURES}

Between March 25, 2005, and May 7, 2007, a total of 3602 patients, at 123 centers in 11 countries, who had ST-segment elevation myocardial infarction and were undergoing primary PCI were randomly assigned to treatment with heparin plus a glycoprotein IIb/IIIa inhibitor (1802 patients) or with bivalirudin alone (1800 patients) (Fig. 1). After emergency angiography, the primary management strategy was primary $\mathrm{PCI}$ in $92.7 \%$ of the patients, deferred $\mathrm{PCI}$ in $0.2 \%$, primary CABG in $1.7 \%$, and medical management in 5.3\%.

The baseline features of the groups were well matched (Table 1). The median age was 60.2 years, and $76.6 \%$ of the patients were men. The infarctrelated vessel was the left anterior descending artery in $40.7 \%$ of the patients who were undergoing primary PCI, and stents were implanted in $95.5 \%$ of those patients. Compliance with protocol-specified study medications was high (Table 2). Unfractionated heparin (typically a bolus without infusion) was administered before cardiac catheterization in approximately two thirds of the patients who were assigned to treatment with bivalirudin. A 600-mg loading dose of clopidogrel was used almost twice as frequently as a $300-\mathrm{mg}$ dose. Glycoprotein IIb/IIIa inhibitors were administered in 129 patients (7.2\%) who were assigned to bivalirudin treatment - in 47 because of a sustained absence of reflow after PCI, in 32 because of giant thrombus after PCI, and in the rest for various other clinical indications.

\section{CLINICAL OUTCOMES}

At 30 days, patients who were assigned to receive bivalirudin alone, as compared with those who were assigned to receive heparin plus a glycoprotein IIb/IIIa inhibitor, had a significantly reduced rate of net adverse clinical events $(9.2 \%$ vs. $12.1 \%$; relative risk, 0.76; 95\% confidence interval [CI], 0.63 to $0.92 ; \mathrm{P}=0.005$ ), owing to a lower rate of major bleeding ( $4.9 \%$ vs. $8.3 \%$; relative risk, 0.60 ; $95 \%$ CI, 0.46 to $0.77 ; \mathrm{P}<0.001$ ), with similar rates of major adverse cardiovascular events $(5.4 \%$ and $5.5 \%$, respectively; relative risk in the bivalirudin group, $0.99 ; 95 \% \mathrm{CI}, 0.76$ to $1.30 ; \mathrm{P}=0.95$ ) (Table 3 and Fig. 2). In a post hoc analysis, with the exclusion of large hematomas from the protocol definition, the rate of major bleeding was reduced from $7.8 \%$ with heparin plus glycoprotein IIb/IIIa inhibitors to $4.7 \%$ with bivalirudin ( $\mathrm{P}<0.001$ ). Bivalirudin, as compared with heparin plus glycoprotein IIb/IIIa inhibitors, also reduced hemorrhagic complications as defined by the TIMI and GUSTO scales, thrombocytopenia, and the need for blood transfusions (Table 3). Among patients in the control group, the peak activated clotting time did not differ significantly between those with major bleeding and those without major bleeding (median, 273 seconds and 263 seconds, respectively; $\mathrm{P}=0.12$ ).

Treatment with bivalirudin, as compared with heparin plus glycoprotein IIb/IIIa inhibitors, resulted in significantly lower 30-day rates of death from cardiac causes $(1.8 \%$ vs. $2.9 \%$; relative risk, $0.62 ; 95 \% \mathrm{CI}, 0.40$ to $0.95 ; \mathrm{P}=0.03$ ) and death from all causes $(2.1 \%$ vs. $3.1 \%$; relative risk, 0.66 ; $95 \%$ CI, 0.44 to $1.00 ; \mathrm{P}=0.047$ ); rates of reinfarction, target-vessel revascularization, and stroke were not significantly different (Table 3 and Fig. 2). There were no significant differences in the peak creatine kinase level or creatine kinase MB fraction between the bivalirudin group and the group that received heparin plus glycoprotein IIb/IIIa inhibitors (median peak creatine kinase level, 1433.0 U per liter and 1428.5 U per liter, respectively; $\mathrm{P}=0.79$; median peak creatine kinase $\mathrm{MB}$ fraction, 162.8 U per liter and 160.1 U per liter, respectively; $\mathrm{P}=0.98$ ). There were no significant 


\begin{tabular}{|c|c|c|}
\hline Characteristic & $\begin{array}{c}\text { Heparin plus a } \\
\text { Glycoprotein IIb/IIIa } \\
\text { Inhibitor ( } \mathrm{N}=1802)\end{array}$ & $\begin{array}{l}\text { Bivalirudin Alone } \\
\qquad(\mathrm{N}=1800)\end{array}$ \\
\hline \multicolumn{3}{|l|}{ Age $-y r$} \\
\hline Median & 60.7 & 59.8 \\
\hline Range & $21.6-91.6$ & $26.0-92.3$ \\
\hline Male sex - no. (\%) & $1372(76.1)$ & $1388(77.1)$ \\
\hline \multicolumn{3}{|l|}{ Diabetes - no./total no. (\%) } \\
\hline Any & $312 / 1800(17.3)$ & $281 / 1799(15.6)$ \\
\hline Insulin-requiring & $87 / 1800(4.8)$ & $72 / 1799(4.0)$ \\
\hline Hypertension — no./total no. (\%) & $993 / 1800(55.2)$ & $931 / 1799(51.8)$ \\
\hline Hyperlipidemia — no./total no. (\%) & $769 / 1800(42.7)$ & $781 / 1798(43.4)$ \\
\hline Current smoker — no./total no. (\%) & $807 / 1792(45.0)$ & $845 / 1789(47.2)$ \\
\hline Prior myocardial infarction — no./total no. (\%) & $205 / 1800(11.4)$ & $187 / 1799(10.4)$ \\
\hline Prior percutaneous coronary intervention - no./total no. (\%) & $198 / 1800(11.0)$ & $188 / 1799(10.5)$ \\
\hline Prior coronary-artery bypass grafting — no./total no. (\%) & $46 / 1800(2.6)$ & $59 / 1799(3.3)$ \\
\hline \multicolumn{3}{|l|}{ Weight - kg } \\
\hline Median & 80.0 & 80.0 \\
\hline Interquartile range & $71.0-90.0$ & $71.0-90.3$ \\
\hline \multicolumn{3}{|l|}{ Interval from symptom onset to hospital arrival - $\mathrm{hr}$} \\
\hline Median & 2.1 & 2.2 \\
\hline Interquartile range & $1.3-3.9$ & $1.3-4.0$ \\
\hline Killip class II, III, or IV — no./total no. (\%) & $152 / 1797(8.5)$ & $153 / 1795(8.5)$ \\
\hline Renal insufficiency - no./total no. $(\%) \dagger$ & $292 / 1676(17.4)$ & $262 / 1661(15.8)$ \\
\hline Anemia — no./total no. (\%) $\leftarrow$ & $181 / 1692(10.7)$ & $175 / 1693(10.3)$ \\
\hline Thrombocytopenia - no./total no. (\%)』 & $80 / 1733(4.6)$ & $64 / 1729(3.7)$ \\
\hline \multicolumn{3}{|l|}{ Left ventricular ejection fraction — \%ף } \\
\hline Median & 50 & 50 \\
\hline Interquartile range & $41-59$ & $45-60$ \\
\hline
\end{tabular}

* There were no significant differences between groups, except for hypertension $(\mathrm{P}=0.04)$.

$\uparrow$ Renal insufficiency was defined as a creatinine clearance of less than $60 \mathrm{ml}$ per minute as calculated at baseline by the Cockcroft-Gault equation.

$\lceil$ Anemia was defined, according to the World Health Organization criteria, as a hematocrit value at initial presentation of less than $39 \%$ for men and less than $36 \%$ for women.

$\int$ Thrombocytopenia was defined as less than 150,000 cells per cubic millimeter at baseline.

I Left ventricular ejection fraction was assessed visually on the contrast-enhanced left ventriculogram obtained at baseline.

interactions between the treatment assignment and either preprocedural unfractionated-heparin use or clopidogrel loading dose with respect to major adverse cardiovascular events or major bleeding (Table 4).

Among 3124 patients in whom stents were successfully implanted, the overall rate of stent thrombosis at 30 days did not differ significantly between the group that received bivalirudin and the group that received heparin plus a glycoprotein
IIb/IIIa inhibitor (2.5\% and $1.9 \%$, respectively; $\mathrm{P}=0.30$ ). However, in a prespecified analysis, within the first 24 hours, stent thrombosis occurred in 17 more patients in the bivalirudin group than in the group receiving heparin plus a glycoprotein IIb/IIIa inhibitor ( $1.3 \%$ vs. $0.3 \%, \mathrm{P}<0.001)$, whereas between 24 hours and 30 days, stent thrombosis occurred in 7 fewer patients in the bivalirudin group $(1.2 \%$ vs. $1.7 \%, \mathrm{P}=0.28)$. Nonetheless, patients in whom PCI was performed and who were 


\begin{tabular}{|c|c|c|}
\hline Variable & $\begin{array}{l}\text { Heparin plus a } \\
\text { Glycoprotein IIb/IIla } \\
\text { Inhibitor }(\mathrm{N}=1802)\end{array}$ & $\begin{array}{l}\text { Bivalirudin Alone } \\
(\mathrm{N}=1800)\end{array}$ \\
\hline \multicolumn{3}{|l|}{ Infarct-related artery — no./total no. (\%) } \\
\hline Left anterior descending & $747 / 1778(42.0)$ & $700 / 1781(39.3)$ \\
\hline Left circumflex & $269 / 1778(15.1)$ & $293 / 1781(16.5)$ \\
\hline Right & $738 / 1778(41.5)$ & $757 / 1781(42.5)$ \\
\hline Left main & $7 / 1778(0.4)$ & $13 / 1781(0.7)$ \\
\hline Saphenous-vein graft & $17 / 1778(1.0)$ & $17 / 1781(1.0)$ \\
\hline Internal thoracic & $0 / 1778$ & $1 / 1781(0.1)$ \\
\hline Stent implanted (among PCl patients) — no./total no. (\%) & $1553 / 1628(95.4)$ & $1571 / 1643(95.6)$ \\
\hline Heparin before procedure - no./total no. (\%) & $1371 / 1798(76.3)$ & $1182 / 1797(65.8)$ \\
\hline \multicolumn{3}{|l|}{ Antithrombin during procedure - no./total no. (\%) } \\
\hline Heparin & $1778 / 1798(98.9)$ & $46 / 1796(2.6)$ \\
\hline Bivalirudin & $4 / 1787(0.2)$ & $1741 / 1797(96.9)$ \\
\hline \multicolumn{3}{|l|}{ Peak activated clotting time $-\mathrm{sec}$} \\
\hline Median & 264 & 357 \\
\hline Interquartile range & $228-320$ & $300-402$ \\
\hline \multicolumn{3}{|l|}{ Glycoprotein IIb/IIla inhibitor use — no./total no. (\%) } \\
\hline During cardiac catheterization & $1699 / 1798(94.5)$ & $129 / 1792(7.2)$ \\
\hline During primary $\mathrm{PCl}$ & $1623 / 1661(97.7)$ & $126 / 1674(7.5)$ \\
\hline Abciximab & $863 / 1661(52.0)$ & $72 / 1674(4.3)$ \\
\hline Eptifibatide & $757 / 1661(45.6)$ & $53 / 1674(3.2)$ \\
\hline Tirofiban & $3 / 1661(0.2)$ & $2 / 1674(0.1)$ \\
\hline \multicolumn{3}{|l|}{ Aspirin use - no./total no. (\%) } \\
\hline Before admission & $486 / 1798(27.0)$ & $482 / 1795(26.9)$ \\
\hline During hospitalization & $1795 / 1798(99.8)$ & $1791 / 1797(99.7)$ \\
\hline At discharge & $1697 / 1748(97.1)$ & $1729 / 1762(98.1)$ \\
\hline \multicolumn{3}{|l|}{ Thienopyridine use — no./total no. (\%) } \\
\hline Before admission & $80 / 1798(4.4)$ & $63 / 1795(3.5)$ \\
\hline \multicolumn{3}{|l|}{ Loading dose at time of admission } \\
\hline Clopidogrel, 300 mg & $618 / 1798(34.4)$ & $595 / 1797(33.1)$ \\
\hline Clopidogrel, 600 mg & $1091 / 1798(60.7)$ & $1125 / 1797(62.6)$ \\
\hline Clopidogrel, other or unknown & $89 / 1798(4.9)$ & $77 / 1797(4.3)$ \\
\hline Ticlopidine & $7 / 1797(0.4)$ & $8 / 1795(0.4)$ \\
\hline During hospitalization & $1766 / 1798(98.2)$ & $1772 / 1796(98.7)$ \\
\hline At discharge & $1621 / 1748(92.7)$ & $1652 / 1764(93.7)$ \\
\hline \multicolumn{3}{|l|}{ Other medications at discharge - no./total no. (\%) } \\
\hline Beta-blockers & $1575 / 1747(90.2)$ & $1598 / 1763(90.6)$ \\
\hline ACE inhibitors or angiotensin-receptor blockers & $1437 / 1749(82.2)$ & $1402 / 1763(79.5)$ \\
\hline Statins & $1641 / 1749(93.8)$ & $1652 / 1763(93.7)$ \\
\hline
\end{tabular}

* ACE denotes angiotensin-converting enzyme, and PCI percutaneous coronary intervention. $\uparrow$ Some patients had more than one vessel treated during the index procedure. 
assigned to receive bivalirudin rather than heparin plus a glycoprotein IIb/IIIa inhibitor had lower 30 -day rates of death from cardiac causes $(1.8 \%$ vs. $2.8 \%$; relative risk, 0.63 ; $95 \% \mathrm{CI}, 0.40$ to 0.99 ; $\mathrm{P}=0.045)$, major bleeding ( $5.1 \%$ vs. $8.5 \%$; relative risk, 0.59 ; $95 \% \mathrm{CI}, 0.46$ to 0.77 ; $\mathrm{P}<0.001$ ), and net adverse clinical events $(9.2 \%$ vs. $12.2 \%$; relative risk, 0.75 ; $95 \% \mathrm{CI}, 0.62$ to $0.92 ; \mathrm{P}=0.005$ ).

Among the 25 patients in whom stent thrombosis developed within 24 hours, 2 patients died (8.0\%), including 1 in each randomized group. In the entire study cohort, of the 93 patients who died within 30 days, death was preceded by major bleeding in 26 patients, 8 of whom were in the bivalirudin group (hazard ratio for death among patients with vs. those without major bleeding, 9.12; $95 \%$ CI, 5.73 to 14.52 ; $\mathrm{P}<0.001$ ) and by definite stent thrombosis in 5 patients, 1 of whom was in the bivalirudin group (hazard ratio for death among patients with vs. those without definite stent thrombosis, 5.54; 95\% CI, 2.24 to 13.69; $\mathrm{P}<0.001)$.

\section{DISCUSSION}

In this prospective, randomized trial involving patients with ST-segment elevation myocardial infarction who were undergoing primary PCI, treatment with the direct thrombin inhibitor bivalirudin (with glycoprotein IIb/IIIa inhibitors administered in $7.2 \%$ of the patients because of suboptimal results of the PCI), as compared with treatment with heparin plus the routine use of glycoprotein IIb/IIIa inhibitors, improved eventfree survival at 30 days, owing to a significant reduction in major bleeding. The rates of major adverse cardiovascular events were similar in the two treatment groups. Bivalirudin reduced the rate of major bleeding, as classified not only by the protocol definition but also by the laboratory-based TIMI scale and the clinical GUSTO scale, and in addition reduced the rates of thrombocytopenia and blood transfusion, despite the significantly higher peak activated clotting time among patients treated with bivalirudin. Moreover, random assignment to bivalirudin alone as compared with heparin plus glycoprotein IIb/IIIa inhibitors significantly reduced the rates of death from cardiac causes and from all causes at 30 days.

The reduction in mortality with bivalirudin as compared with heparin plus glycoprotein IIb/IIIa inhibitors in the present trial may be attributable to the prevention of iatrogenic hemorrhagic complications. Previous trials have documented the independent relationship between major bleeding (with or without blood transfusions) and subsequent death. ${ }^{16-19}$ Major bleeding was a more powerful predictor of death than periprocedural myocardial infarction after PCI in the Randomized Evaluation of PCI Linking Angiomax to Reduced Clinical Events 2 (REPLACE-2) trial, and the reduction in bleeding with bivalirudin as compared with heparin plus glycoprotein IIb/IIIa inhibitors resulted in a trend toward reduced late mortality after PCI among the relatively low-risk patients in that study. ${ }^{27}$ In the present trial, more deaths occurred after major bleeding ( 26 deaths) than after reinfarction (10) or definite stent thrombosis (5). The $40 \%$ relative reduction in major bleeding in the bivalirudin group as compared with the group that received heparin plus a glycoprotein IIb/IIIa inhibitor, with similar rates of ischemic complications, may thus explain the observed improvement in survival with bivalirudin in patients with STsegment elevation myocardial infarction, who are at higher risk than the patients in the REPLACE-2 trial. Moreover, anticoagulation with bivalirudin reduced the occurrence of severe thrombocytopenia, which has also been strongly associated with death among patients with ST-segment elevation myocardial infarction and with PCI. ${ }^{14,15}$

Among patients in whom a stent was successfully implanted, assignment to bivalirudin, as compared with heparin plus glycoprotein IIb/IIIa inhibitors, resulted in 17 more episodes of stent thrombosis within the first 24 hours, representing a significant $1.0 \%$ absolute increase, which was partially offset by 7 fewer events in the patients treated with bivalirudin between 24 hours and 30 days (absolute reduction, $0.5 \%$ ). The early increase in stent thrombosis with bivalirudin alone may be explained by adenosine diphosphateinduced platelet activation before maximal thienopyridine blockade of the $\mathrm{P}_{2} \mathrm{Y}_{12}$ receptor ${ }^{28}$ or by residual thrombin activity after the discontinuation of bivalirudin. However, although the increase in acute thrombotic events probably underlies the increased risk of major adverse cardiovascular events that was noted on the first day among patients treated with bivalirudin, the overall 30-day rates of reinfarction were not increased $-1.8 \%$ in each group - and only 2 of the 93 deaths in the study occurred after acute stent thrombosis ( 1 in each randomized group). The prognostic im- 


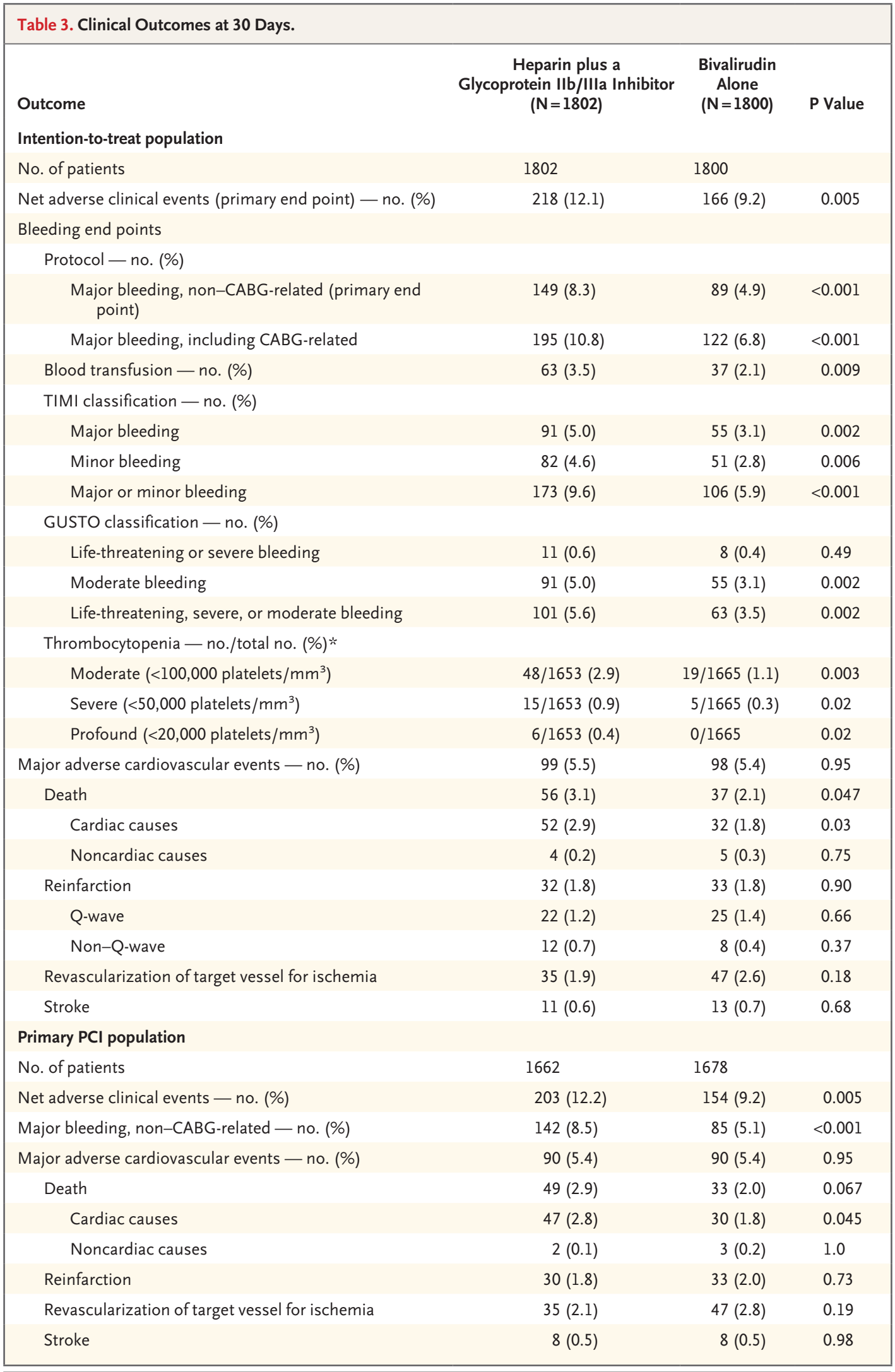




\begin{tabular}{|c|c|c|c|}
\hline Table 3. (Continued.) & & & \\
\hline Outcome & $\begin{array}{c}\text { Heparin plus a } \\
\text { Glycoprotein Ilb/IIla Inhibitor } \\
\qquad(\mathrm{N}=1802)\end{array}$ & $\begin{array}{c}\text { Bivalirudin } \\
\text { Alone } \\
(\mathrm{N}=1800)\end{array}$ & P Value \\
\hline \multicolumn{4}{|l|}{ Patients with stents implanted } \\
\hline No. of patients & 1553 & 1571 & \\
\hline Stent thrombosis, protocol definition - no. (\%) $\dagger$ & $30(1.9)$ & $39(2.5)$ & 0.30 \\
\hline Definite & $22(1.4)$ & $35(2.2)$ & 0.09 \\
\hline Probable & $8(0.5)$ & $4(0.3)$ & 0.24 \\
\hline Acute $(\leq 24 \mathrm{hr})$ & $4(0.3)$ & $21(1.3)$ & $<0.001$ \\
\hline Subacute ( $>24 \mathrm{hr}-30$ days) & $26(1.7)$ & $19(1.2)$ & 0.28 \\
\hline
\end{tabular}

* Patients with a baseline platelet count of less than 150,000 cells per cubic millimeter were not included in the analysis. CABG denotes coronary-artery bypass grafting, GUSTO Global Utilization of Streptokinase and Tissue Plasminogen Activator for Occluded Coronary Arteries, PCI percutaneous coronary intervention, and TIMI Thrombolysis in Myocardial Infarction.

$\uparrow$ The protocol definition of stent thrombosis was definite or probable thrombosis occurring within 30 days, according to the Academic Research Consortium criteria.

plications of acute stent thrombosis that occurs early in the hospital phase in closely monitored patients who have undergone primary PCI for STsegment elevation myocardial infarction and that affects a previously infarcted myocardial territory may thus differ from the implications of subacute stent thrombosis or acute thrombosis that occurs after discharge from the hospital in patients who have undergone elective PCI and whose left ventricular function was well preserved. Most important, the rate of death from cardiac causes (including deaths due to stent thrombosis) among patients who were treated with heparin plus a glycoprotein IIb/IIIa inhibitor surpassed that among patients treated with bivalirudin by day 7 , and by 30 days, a significant $37.9 \%$ relative reduction in death from cardiac causes (an absolute decrease of $1.1 \%$ ) was seen in the group treated with bivalirudin. Further investigation is warranted to determine whether the risk of early stent thrombosis can be mitigated by treatment with more rapidly acting and potent thienopyridine agents, ${ }^{29,30}$ a longer course of bivalirudin, or both, without increasing the risk of bleeding. Pending such studies, the $1 \%$ incremental risk of stent thrombosis within the first 24 hours, with no significant difference in the rates at 30 days, must be placed in the context of the decrease in the rate of major bleeding and the subsequent $1 \%$ absolute reduction in mortality from cardiac causes that were achieved with the abbreviated use of bivalirudin (i.e., only during PCI) as compared with heparin plus glycoprotein IIb/IIIa inhibitors.
The present study has several strengths, including the enrollment of a broad cross section of patients. Nonetheless, several limitations should be noted. First, the logistic complexities of the trial necessitated an open-label design, introducing potential bias. However, compliance with the protocol procedure and the study medications was high, and the rate of provisional use of glycoprotein IIb/IIIa inhibitors in the bivalirudin group was low and similar to that in the double-blind REPLACE-2 trial. ${ }^{20}$ The relative reductions in hemorrhagic complications with bivalirudin as compared with heparin plus glycoprotein IIb/IIIa inhibitors in the present trial were also similar to those in the REPLACE-2 trial. ${ }^{20}$ Potential bias was further mitigated by the use of blinded core laboratories and a clinical-event adjudication committee that required original-source documentation for event verification. Second, a heparin bolus was administered in the emergency room to approximately two thirds of the patients, with bivalirudin most commonly started in the cardiac catheterization laboratory 30 minutes later, before PCI. Interaction testing, however, showed that administration of bivalirudin significantly reduced major bleeding independently of preprocedural administration of heparin, and preprocedural administration of heparin before bivalirudin was associated with a weak trend toward reduced major adverse cardiovascular events at 30 days. Third, the trial was underpowered for low-frequency end points, including death. However, the mechanistic underpinnings for the observed reduction in 


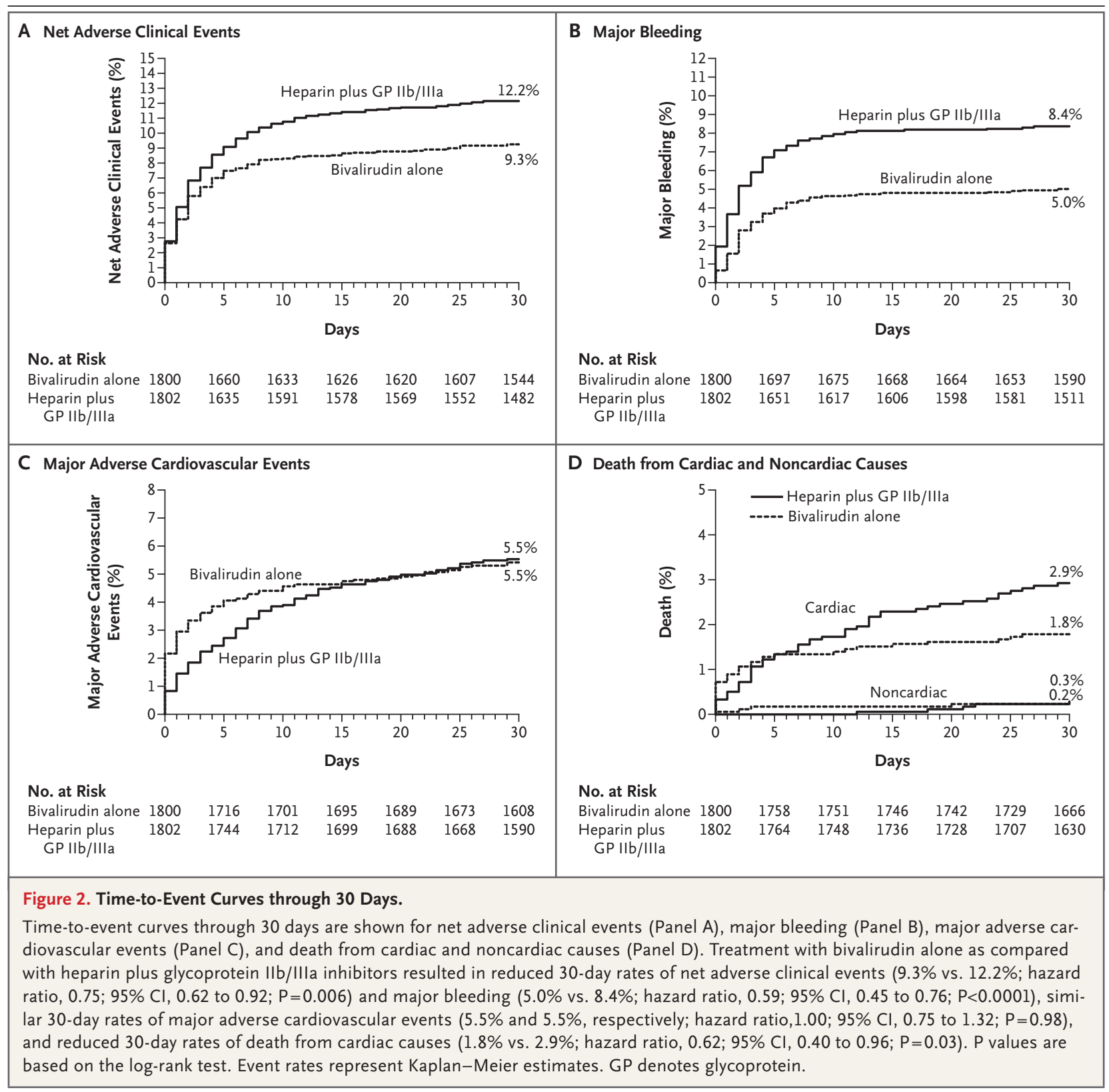

the rate of death with bivalirudin (i.e., reduced risks of bleeding, transfusion, and thrombocytopenia), in concert with the consistency of our results with those of earlier studies, ${ }^{20-23}$ provide reassurance that this finding is probably valid. Fourth, reinfarction may be difficult to detect after primary PCI, although the nearly identical peak levels of cardiac enzymes after PCI in the two treatment groups suggest that there was no difference in the rate of reinfarction. Finally, although an independent, unblinded statistical monitoring group has found no interactions between the type of stent used and the randomly assigned study drug for the primary 30-day end points, longerterm follow-up, including unblinding of the stent randomization data at 1 year, is required to evaluate thoroughly the effect of bivalirudin in patients with ST-segment elevation myocardial infarction who are undergoing primary PCI.

In conclusion, our trial shows that in patients with evolving ST-segment elevation myocardial infarction who are undergoing primary PCI, the 


\begin{tabular}{|c|c|c|c|c|}
\hline \multirow[t]{2}{*}{ Adverse Event } & $\begin{array}{l}\text { Bivalirudin } \\
\text { Alone }\end{array}$ & $\begin{array}{l}\text { Heparin plus a } \\
\text { Glycoprotein } \\
\text { Ilb/IIla Inhibitor }\end{array}$ & $\begin{array}{l}\text { Relative Risk } \\
(95 \% \mathrm{Cl}) *\end{array}$ & $\begin{array}{l}\mathrm{P} \text { Value for } \\
\text { Interaction }\end{array}$ \\
\hline & \multicolumn{2}{|c|}{ no./total no. (\%) } & & \\
\hline \multicolumn{5}{|c|}{ Major adverse cardiovascular events } \\
\hline \multicolumn{5}{|c|}{ Unfractionated heparin before procedure } \\
\hline Yes & $54 / 1182(4.6)$ & $77 / 1371(5.6)$ & $0.81(0.58-1.14)$ & 0.08 \\
\hline No & $44 / 615(7.2)$ & $22 / 427(5.2)$ & $1.39(0.85-2.28)$ & \\
\hline \multicolumn{5}{|c|}{ Clopidogrel loading dose } \\
\hline $300 \mathrm{mg}$ & $43 / 595(7.2)$ & $43 / 618(7.0)$ & $1.04(0.69-1.56)$ & 0.76 \\
\hline $600 \mathrm{mg}$ & $46 / 1125(4.1)$ & $47 / 1091(4.3)$ & $0.95(0.64-1.41)$ & \\
\hline \multicolumn{5}{|c|}{ Major bleeding (protocol-defined) } \\
\hline \multicolumn{5}{|c|}{ Unfractionated heparin before procedure } \\
\hline Yes & $57 / 1182(4.8)$ & $117 / 1371(8.5)$ & $0.57(0.42-0.77)$ & 0.47 \\
\hline No & $32 / 615(5.2)$ & $32 / 427(7.5)$ & $0.69(0.43-1.12)$ & \\
\hline \multicolumn{5}{|c|}{ Clopidogrel loading dose } \\
\hline $300 \mathrm{mg}$ & $38 / 595(6.4)$ & $64 / 618(10.4)$ & $0.62(0.42-0.91)$ & 0.74 \\
\hline $600 \mathrm{mg}$ & $47 / 1125(4.2)$ & $82 / 1091(7.5)$ & $0.56(0.39-0.79)$ & \\
\hline
\end{tabular}

* The relative risk is for the patients assigned to receive bivalirudin as compared with those assigned to receive heparin plus glycoprotein Ilb/IIla inhibitors. $\mathrm{PCl}$ denotes percutaneous coronary intervention.

use of bivalirudin alone, as compared with heparin plus a glycoprotein IIb/IIIa inhibitor, results in significantly reduced 30-day rates of major bleeding and increased event-free survival.

Supported by the Cardiovascular Research Foundation, with grant support from Boston Scientific and the Medicines Company.

Dr. Stone reports receiving consulting fees from Medtronic, GlaxoSmithKline, Eli Lilly, and Bristol-Myers Squibb and grant support from Boston Scientific, the Medicines Company, and Abbott Vascular. Dr. Guagliumi reports receiving consulting fees from or serving on advisory boards for Abbott Vascular and Boston Scientific and receiving grant support from Medtronic and Boston Scientific. Dr. Dudek reports receiving lecture fees from Nycomed. Dr. Gersh reports receiving consulting fees from or serving on advisory boards for AstraZeneca, BristolMyers Squibb, Abbott Laboratories, and Boston Scientific and having equity interest in CV Therapeutics. Dr. Pocock reports receiving consulting fees from and serving on an advisory board for the Medicines Company. Dr. Kirtane reports receiving consulting fees from or serving on advisory boards for Abbott Vascular, Medtronic, and Boston Scientific and receiving lecture fees from the Medicines Company and Alphamedica. Dr. Mehran reports receiving lecture fees from Boston Scientific and the Medicines Company. Dr. Parise reports being employed by the Cardiovascular Research Foundation. No other potential conflict of interest relevant to this article was reported.

\section{APPENDIX}

The following investigators and institutions participated in the HORIZONS-AMI Trial: Executive Committee: G.W. Stone (principal investigator and chair), Columbia University Medical Center and the Cardiovascular Research Foundation, New York; B.R. Brodie, LeBauer Cardiovascular Research Foundation and Moses Cone Hospital, Greensboro, NC; D.A. Cox, Mid Carolina Cardiology, Charlotte, NC; C.L. Grines, William Beaumont Hospital, Royal Oak, MI; B.D. Rutherford, St. Luke's Hospital, Kansas City, MO. Pharmacology Committee: D. Bhatt, Cleveland Clinic Foundation, Cleveland; G. Dangas, Columbia University Medical Center and the Cardiovascular Research Foundation, New York; F. Feit, New York University, New York; M. Ohman, Duke University Medical Center, Durham, NC. European Steering Committee: H. Bonnier, Catharina Hospital, Eindhoven, the Netherlands; A. Colombo, Colombus Hospital, Milan; E. Garcia, Hospital Universitario Gregorio Maranon, Madrid; E. Grube, Heart Center Siegburg, Siegburg, Germany; G. Guagliumi, Ospedali Riuniti di Bergamo, Bergamo, Italy; A. Kastrati, Deutsches Herzzentrum, Technische Universität, Munich, Germany; P. Serruys, Thoraxcenter, Rotterdam, the Netherlands; H. Suryapranata, Hospital De Weezenlanden, Zwolle, the Netherlands. Country Leaders: the Netherlands: H. Bonnier and H. Suryapranata; Italy: A. Colombo and G. Guagliumi; Spain: E. Garcia; Germany: E. Grube and A. Kastrati; Israel: Y. Almagor; United Kingdom: A. Banning; Argentina: J. Belardi, L. Grinfeld; Poland: D. Dudek; Austria: K. Huber; Norway: D. Nilsen; Sweden: G. Olivecrona; Denmark: L. Rasmussen. Clinical Endpoints Committee: Cardiovascular Research Foundation Data Center, New York, S.C. Wong (chair). Field Officers: M. Farkouh (chair), M. Attubato, G. Dangas, F. Feit, R. Mehran. Site Management and Data Monitoring: J. Tyson and Associates (U.S.), D-Target (Europe), Tango (South America). Data Management: E-trials, Morrisville, NC, D. Winsted (manager). Data Coordination and Analysis: Cardiovascular Research Foundation Data Center, New York, R. Mehran (director), I. Bihl (operations), H. Parise (statistics). Data Safety and Monitoring Board: B.J. Gersh (chair), Mayo Clinic, 
Rochester, MN; D. Faxon, Brigham and Women's Hospital, Boston; S. King, Fuqua Heart Center, Atlanta; S.J. Pocock, London School of Hygiene and Tropical Medicine, London; D.O. Williams, Rhode Island Hospital, Providence, RI. Qualitative and Quantitative Coronary Angiographic Core Laboratory Analysis: Cardiovascular Research Foundation, New York, A.J. Lansky (director), E. Cristea (operations). Qualitative and Quantitative Electrocardiographic Core Laboratory Analysis: Cardiovascular Research Foundation, New York, J. Reiffel (director). Intravascular Ultrasound Core Laboratory Analysis: Cardiovascular Research Foundation, New York, G. Mintz (director). Biomarker Substudy Core Laboratory: BioSite, San Diego, CA.

For a full list of participating countries (with total enrollment), hospitals, and principal investigators, see the Supplementary Appendix (available with the full text of this article at www.nejm.org).

REFERENCES

1. Keeley EC, Boura JA, Grines CL. Primary angioplasty versus intravenous thrombolytic therapy for acute myocardial infarction: a quantitative review of 23 randomised trials. Lancet 2003;361:13-20.

2. Schömig A, Neumann FJ, Kastrati A, et al. A randomized comparison of antiplatelet and anticoagulant therapy after the placement of coronary-artery stents. N Engl J Med 1996;334:1084-9.

3. Stone GW, Grines CL, Cox DA, et al. Comparison of angioplasty with stenting with or without abciximab, in acute myocardial infarction. N Engl J Med 2002; 346:957-66.

4. De Luca G, Suryapranata H, Ottervanger JP, et al. Comparison between stenting and balloon in elderly patients undergoing primary angioplasty for ST-segment elevation myocardial infarction. Int J Cardiol 2007;119:306-9.

5. De Luca G, Suryapranata H, Stone GW, Antoniucci D, Neumann FJ, Chiarello M. Adjunctive mechanical devices to prevent distal embolization in patients undergoing mechanical revascularization for acute myocardial infarction: a metaanalysis of randomized trials. Am Heart J 2007;153:343-53.

6. Ross AM, Gibbons RJ, Stone GW, Kloner RA, Alexander RW. A randomized, double-blinded, placebo-controlled multicenter trial of adenosine as an adjunct to reperfusion in the treatment of acute myocardial infarction (AMISTAD-II). J Am Coll Cardiol 2005;45:1775-80.

7. Armstrong $\mathrm{PW}$, Granger CB, Adams PX, et al. Pexelizumab for acute ST-elevation myocardial infarction in patients undergoing primary percutaneous coronary intervention: a randomized controlled trial. JAMA 2007;297:43-51.

8. Alexander JH, Reynolds HR, Stebbins $\mathrm{AL}$, et al. Effect of tilarginine acetate in patients with acute myocardial infarction and cardiogenic shock: the TRIUMPH randomized controlled trial. JAMA 2007;297: 1657-66.

9. De Luca G, Suryapranata H, Stone GW, et al. Abciximab as adjunctive therapy to reperfusion in acute ST-segment elevation myocardial infarction: a meta-analysis of randomized trials. JAMA 2005;293:175965.

10. Kandzari DE, Hasselblad V, Tcheng $\mathrm{JE}$, et al. Improved clinical outcomes with abciximab therapy in acute myocardial infarction: a systematic overview of ran- domized clinical trials. Am Heart J 2004; 147:457-62.

11. Dauerman HL, Frederick PD, Miller D French WJ. Current incidence and clinical outcomes of bivalirudin administration among patients undergoing primary coronary intervention for stent thrombosis elevation acute myocardial infarction. Coron Artery Dis 2007;18:141-8.

12. Fox KA, Steg PG, Eagle KA, et al. Decline in rates of death and heart failure in acute coronary syndromes, 1999-2006. JAMA 2007;297:1892-900.

13. Montalescot G, Barragan P, Wittenberg O, et al. Platelet glycoprotein IIb/III inhibition with coronary stenting for acute myocardial infarction. $N$ Engl J Med 2001; 344:1895-903.

14. Kereiakes DJ, Berkowitz SD, Lincoff $\mathrm{AM}$, et al. Clinical correlates and course of thrombocytopenia during percutaneous coronary intervention in the era of abciximab platelet glycoprotein IIb/IIIa blockade. Am Heart J 2000;140:74-80.

15. Nikolsky E, Grines CL, Cox DA, et al. Impact of baseline platelet count in patients undergoing primary percutaneous coronary intervention in acute myocardial infarction (from the CADILLAC trial). Am J Cardiol 2007;99:1055-61.

16. Eikelboom JW, Mehta SR, Anand SS Xie C, Fox KA, Yusuf S. Adverse impact of bleeding on prognosis in patients with acute coronary syndromes. Circulation 2006;114:774-82

17. Kinnaird TD, Stabile E, Mintz GS, et al. Incidence, predictors, and prognostic implications of bleeding and blood transfusion following percutaneous coronary interventions. Am J Cardiol 2003;92:930-5. 18. Rao SV, Jollis JG, Harrington RA, et al. Relationship of blood transfusion and clinical outcomes in patients with acute coronary syndromes. JAMA 2004;292:1555-62.

19. Manoukian SV, Feit F, Mehran R, et al. Impact of major bleeding on 30-day mortality and clinical outcomes in patients with acute coronary syndromes: an analysis from the ACUITY trial. J Am Coll Cardiol 2007;49:1362-8.

20. Lincoff AM, Bittl JA, Harrington RA, et al. Bivalirudin and provisional glycoprotein IIb/IIIa blockade compared with heparin and planned glycoprotein IIb/IIIa blockade during percutaneous coronary intervention: REPLACE-2 randomized trial. JAMA 2003;289:853-63. [Erratum, JAMA 2003;289:1638.]
21. Lincoff AM, Kleiman NS, Kereiakes DJ, et al. Long-term efficacy of bivalirudin and provisional glycoprotein IIb/IIIa blockade vs heparin and planned glycoprotein IIb/IIIa blockade during percutaneous coronary revascularization: REPLACE-2 randomized trial. JAMA 2004;292:696-703. [Erratum, JAMA 2006;296:46.]

22. Stone GW, McLaurin BT, Cox DA, et al. Bivalirudin for patients with acute coronary syndromes. N Engl J Med 2006; 355:2203-16.

23. Stone GW, Ware JH, Bertrand ME, et al. Antithrombotic strategies in patients with acute coronary syndromes undergoing early invasive management: one-year results from the ACUITY trial. JAMA 2007; 298:2497-506.

24. Stone GW, Bertrand M, Colombo A, et al. Acute Catheterization and Urgent Intervention Triage strategY (ACUITY) trial: study design and rationale. Am Heart J 2004;148:764-75.

25. Cutlip DE, Windecker S, Mehran R, et al. Clinical end points in coronary stent trials: a case for standardized definitions. Circulation 2007;115:2344-51.

26. Benjamini Y, Hochberg Y. Controlling the false discovery rate: a practical and powerful approach to multiple testing. J R Stat Soc [B] 1995;57:289-300.

27. Feit F, Voeltz MD, Attubato MJ, et al. Predictors and impact of major hemorrhage on mortality following percutaneous coronary intervention: an analysis of the REPLACE-2 trial. Am J Cardiol 2007;100: 1364-9.

28. Gurbel PA, Bliden KP, Zaman KA, Yoho JA, Hayes KM, Tantry US. Clopidogrel loading with eptifibatide to arrest the reactivity of platelets: results of the Clopidogrel Loading with Eptifibatide to Arrest the Reactivity of Platelets (CLEAR PLATELETS) study. Circulation 2005;111:1153-9.

29. Wiviott SD, Braunwald E, McCabe $\mathrm{CH}$, et al. Prasugrel versus clopidogrel in patients with acute coronary syndromes. N Engl J Med 2007;357:2001-15.

30. Greenbaum $\mathrm{AB}$, Ohman EM, Gibson $\mathrm{CM}$, et al. Preliminary experience with intravenous P2Y12 platelet receptor inhibition as an adjunct to reduced-dose alteplase during acute myocardial infarction: results of the Safety, Tolerability and Effect on Patency in Acute Myocardial Infarction (STEP-AMI) angiographic trial. Am Heart J 2007;154:702-9.

Copyright (C) 2008 Massachusetts Medical Society. 